replacement steroids have not been found. Patients using progestogen-only methods of contraception show hysteroscopic evidence of altered angiogenesis, together with increased microvascular density. Reduced endometrial perfusion in Norplant users (leading to local hypoxia and an upregulation of VEGF expression) may underlie these morphological abnormalities and their presumed clinical correlate of abnormal uterine bleeding. ${ }^{12}$ An increased proliferative tendency has been described in endothelial cells from women with objective menorrhagia, compared to women with normal menstrual blood loss, accompanied by reduced vascular smooth muscle proliferation in the spiral arterioles. Increased angiogenic potential in the peritoneal cavity may be an essential part of the pathogenesis of endometriosis. $^{2}$

It is clear that basic research into angiogenesis in the female reproductive tract has deepened our understanding of reproductive physiology and is beginning to add another level of complexity to what is known about common clinical conditions. ${ }^{2}$ Future work will focus on elaborating these clinical correlations and exploring the use of targeted therapies using factors that alter angiogenesis to treat these conditions. Soluble VEGF receptors, tyrosine kinase inhibitors and inhibitors of MMPs may all be expected to inhibit angiogenesis in vivo. The future carries the potential of using these or similar therapies to treat abnormal bleeding, inhibit the progression of endometriosis and prevent implantation.

\section{Statements on funding and competing interests}

Funding. None identified

Competing interests. Stephen Smith is a Director of Metris Therapeutics Limited and as such receives Director's fees.

Raj Mathur, MRCOG, MD

Subspecialty Trainee, Department of Reproductive Medicine, The Rosie Hospital, Cambridge CB2 2SW, UK
Stephen K Smith, FRCOG, MD

Professor, University Department of Obstetrics and Gynaecology, The Rosie Hospital, Cambridge, CB2 2SW, UK

References

1 Kohnen G, Campbell S, Jeffers MD, et al. Spatially regulated differentiation of endometrial vascular smooth muscle cells. Hum Reprod 2000; 15: 284-292.

2 Smith SK. Regulation of angiogenesis in the endometrium. Trends Endocrinol Metab 2001; 12: 147-151.

3 Rogers PA, Lederman F, Taylor N. Endometrial microvascular growth in normal and dysfunctional states. Hum Reprod Update 1998; 4: 503-508.

4 Neufeld G, Cohen T, Gengrinovitch S, et al. Vascular endothelial growth factor (VEGF) and its receptors. FASEB J 1999; 13: 9-22.

5 Meduri B, Bauseri P, Perrot-Applanat M. Expression of vascular endothelial growth factor receptors in the human endometrium: modulation during the menstrual cycle. Biol Reprod 2000; 62: 439-447.

6 Charnock-Jones DS, Sharkey AM, Rajput-Williams J, et al. Identification and localisation of alternately spliced mRNAs for vascular endothelial growth factor in human uterus and estrogen regulation in endometrial carcinoma cell lines. Biol Reprod 1993; 48: 1120-1128.

7 Torry D S, Holt VJ, Keenan JA, et al. Vascular endothelial growth factor expression in cycling human endometrium. Fertil Steril 1996; 66: $72-80$

8 Hornung D, Lebovic DI, Shifren JL, et al. Vectorial secretion of vascular endothelial growth factor by polarised human endometrial epithelial cells. Fertil Steril 2000; 69: 909-915.

9 Zhang L, Rees MC, Bicknell R. The isolation and long-term culture of normal human endometrial epithelium and stroma. Expression of mRNAs for angiogenic polypeptides basally and on oestrogen and progesterone challenges. J Cell Sci 1995; 108(Pt 1): 323-331.

10 Lau TM, Affandi B, Rogers PAW. The effects of levonorgestrel implants on vascular endothelial growth factor expression in the endometrium. Mol Hum Reprod 1998; 5: 57-63.

11 Maltepe E, Schmidt JV, Baunoch D, et al. Abnormal angiogenesis and responses to glucose and oxygen deprivation in mice lacking the protein ARNT. Nature 1997; 386(6623): 403-407.

12 Hickey M, Fraser IS. Clinical implications of disturbances of uterine vascular morphology and function. Baillieres Clin Obstet Gynaecol 2000; 14: 937-951.

\title{
A woman's right to choose ... counselling!
}

Recently, an anonymous patient sued the National Health Service (NHS) because she wasn't offered counselling after an abortion. Nor was she warned that psychological complications could follow the operation. This legal action raises issues of vital concern to patients, counsellors, the NHS and taxpayers.

Few people relish abortion. Even pro-choice supporters regard it as 'the lesser of two evils'. But while other countries remain divided on the issue, the legal consensus in Britain has ruled that safe medical abortion ought to be available. In the process, however, abortion has sometimes come to be regarded as a 'routine' procedure. This is a serious mistake. Leaving aside the moral debate, an abortion is a totally different experience from having your appendix out. All personnel treating the patient should know this. The psychological issues involved are multiple and profound.

As soon as a woman is aware of any unwanted or accidental pregnancy she is forced to contemplate the immense consequences of any choice she makes:

1. She continues with the pregnancy and rears her child with or without help from the father.

2. She continues with the pregnancy and has the baby adopted.

3. She terminates the pregnancy.

In the first and second cases, there will be a child. She would become the mother. This act would determine many events for the rest of her days. The child would need a name and it would automatically be related to a wider group of people in at least two different families. Many of the relationships in that woman's life, and by definition the future life of the child, would be altered at a stroke. If she continues with the pregnancy and then places her baby for adoption, she has to deal with the issues of detaching from baby. It is likely that she will have all the recognised symptoms of a major bereavement. Third, if she aborts, she may feel full of conflict.

For most women having an abortion is not an easy option but one that is arrived at through painful dialogue with themselves and probably with their partner. Because of this there is often strong ambivalence in the woman leading to resentment, anger and sadness. The idea of a child might awaken many deep-seated anxieties within the mother, especially if she has difficult memories from her own childhood. Or the pregnancy's timing might come to represent a form of doom. One woman said to us: 'It's the story of my life. I always desperately wanted a baby; but not now, and not with him'.

Few patients 'mourn' their appendix when it is removed. Many women who choose abortion still 'mourn' the lost possibilities of the life that will not be. Several years ago the privately funded Post Abortion Counselling Service was 
established in London to cope with these very problems. However, that leaves the rest of the nation and those who cannot pay.

Do all women who undergo abortion need counselling afterwards? No - they need it before they undergo an abortion! If pre-abortion counselling is undertaken then there is less likelihood of post-abortion trauma. ${ }^{1}$ Preabortion counselling offers the opportunity for the woman and her partner to talk about how they think this termination will affect both their lives and their relationship.

Why is abortion not treated in exactly the same way as other areas related to conception? Counselling is part of the package offered to women/couples undergoing in vitro fertilisation (IVF) and assisted conception. An informed discussion is also required for those wishing to adopt a child. Of course, the only people who should ever have formal counselling are those who say they want it. The process has to be voluntary. However, the British Association for Counselling and Psychotherapy (BACP) very firmly believes that anyone who chooses to have an abortion should also be free to choose counselling to help cope with the emotional consequences. It is a basic component of 'a woman's right to choose'.

Pressurising a client to a particular course of action is fundamentally unethical and a contradiction of our profession. The idea of 'informed consent' lies at the heart of our ethical framework and a woman needs to know, for instance, that regret and guilt can follow the decision to continue or terminate a pregnancy. Professional counselling cannot be conducted by those seeking to make converts to a cause either 'pro-life' or 'pro-women's rights'. The moral and political views of the therapist must never be imposed upon the client. It is essential that a person using the title counsellor has been trained and accredited (or working towards accreditation) to BACP standards and maintains supervision. Advice and guidance from a well-meaning health professional with some counselling skills but no formal training and supervision is not counselling. Counselling doesn't happen just because somebody is 'listening'.
Abortion can carry many complex emotional responses that are often paradoxical, e.g. hope and despair or relief and bereavement. In each case the individual needs need to be treated individually. Pat Seber, an experienced BACP counsellor, comments: 'Just as in physical appearance women are different in psychological make-up. Because abortion is not something that most women do on a regular basis but usually only once, they have no yardstick with which to measure their reactions. They don't know how they will feel, they can only guess. Unfortunately if they get it wrong there is no way back and for these women this can turn into severe depression, anxiety, punitive behaviour both towards themselves and others. Often women say "if only I could talk to someone who has had it done". They want to know what they may feel both physically and emotionally. The act of having an abortion is not something that many women want to shout from the rooftops and are often denied the support in coming to terms with the loss which they would have received had it been a miscarriage'.

Overall, there is a 'uniqueness of reaction to a not uncommon experience'. This will decide whether a woman recovers or lapses into depression. Common sense, therefore, suggests that a greater provision of counselling services within the NHS is not just legally prudent - it is essential.

Statements on funding and competing interests

Funding. None identified.

Competing interests. Phillip Hodson's post is in a consultancy capacity for BACP.

Phillip Hodson, MA, FBACP

Head of Media Relations, British Association for Counselling and Psychotherapy (BACP), 1 Regent Place, Rugby, Warwickshire CV21 2PJ, UK. Tel: 08704435252. www.counselling.co.uk

Pat Seber, FBACP

Counsellor, BACP, Rugby, UK

Reference

1 Marcus RJ. Evaluation of abortion counselling. In: Brien J, Fairbairn I (eds), Pregnancy and abortion counselling. London: Routledge,1979.

\section{FROM THE EDITOR}

\section{Beyond FACTs}

If only all the answers to my clinical dilemmas were known and never changed. They are not - and never will be. So I continue to evolve and challenge past custom and idiosyncratic practice with requests for clinical evidence on which to base my decisions. Through all this I need to remain pragmatic and consider my patient's needs in the totality of their social and cultural environment. Evidencebased practice does not always match the needs of the individual; so I need to be explicit and (using patientappropriate language) explain why I might differ from evidence-based medicine (EBM) in individual circumstances. Where did I put that book for recording 'on a named patient basis'? Meanwhile the ever-present lawyer perches vulture-like on my shoulder and the clock ticks as I try to be a perfect decision-maker/communicator and teacher whilst struggling to keep to waiting time initiatives. Does this sound familiar?

Whatever the shortcomings of EBM (the existence of reliable evidence being a major one), this is the future of sound medical practice and a drive for research to provide evidence where none exists. In recognition of the importance of evidence to our current medical practice the Faculty has appointed a new Clinical Effectiveness Unit (CEU) (see pages 176-177). From January 2003 the Journal will publish evidence-based recommendations for clinical practice, produced by the CEU, which will be accompanied by the multiple choice questions (MCQs) and discussion points that you have become familiar with when using the FACTs.

The FACT in this issue (pages 178-181) will therefore be the last. It covers one of the most thorny dilemmas in contraceptive practice - the management of bleeding problems for women using progestogen-only contraception. This is an area of our practice where evidence is often lacking or anecdotal. I do not envy the authors their task. I hope you, as readers, will find their contribution useful and stimulating. I look forward to reading and publishing your letters.

Fran Reader, FRCOG, MFFP

Editor-in-Chief, The Journal of Family Planning and Reproductive Health Care 